\title{
2 Summarizing the impacts of future potential global change scenarios on seawater intrusion at the aquifer scale
}

4 Leticia Baena-Ruiz ${ }^{1}\left({ }^{10} \cdot\right.$ David Pulido-Velazquez $^{2} \cdot$ Antonio-Juan Collados-Lara $^{1}$ - Arianna Renau-Pruñonosa ${ }^{3}$.

5 Ignacio Morell ${ }^{3} \cdot$ Javier Senent-Aparicio ${ }^{4} \cdot$ Carlos Llopis-Albert ${ }^{5}$

6 Received: 14 February 2019/ Accepted: 10 February 2020

7 @ Springer-Verlag GmbH Germany, part of Springer Nature 2020

\section{Abstract}

9 Climate change affects rainfall and temperature producing a breakdown in the water balance and a variation in the dynamic

10 of freshwater-seawater in coastal areas, exacerbating seawater intrusion (SWI) problems. The target of this paper is to propose a method to assess and analyze impacts of future global change (GC) scenarios on SWI at the aquifer scale in a coastal area. Some adaptation measures have been integrated in the definition of future GC scenarios incorporating complementary resources within the system in accordance with urban development planning. The proposed methodology summarizes the 4 impacts of potential GC scenarios in terms of SWI status and vulnerability at the aquifer scale through steady pictures (maps and conceptual 2D cross sections for specific dates or statistics of a period) and time series for lumped indices. It is applied to the Plana de Oropesa-Torreblanca aquifer. The results summarize the influence of GC scenarios in the global status and vulnerability to SWI under some management scenarios. These GC scenarios would produce higher variability of SWI status and vulnerability.

Keywords Global change impacts - Adaptation measures - Seawater intrusion - Status and vulnerability · Coastal aquifer · Lumped index

\section{Introduction}

It is a fact that climate change (CC) would imply a variation in the patterns of temperature and precipitation in the future. In general, in the Mediterranean area an increase

This article is a part of the Topical Collection in Environmental Earth Sciences on "Impacts of Global Change on Groundwater in Western Mediterranean Countries", guest edited by Maria Luisa Calvache, Carlos Duque and David Pulido-Velazquez.

Leticia Baena-Ruiz

lbaenar@gmail.com

David Pulido-Velazquez

d.pulido@igme.es

Antonio-Juan Collados-Lara ajcollados@gmail.com

Arianna Renau-Pruñonosa arenau@uji.es

Ignacio Morell morell@uji.es

Javier Senent-Aparicio jsenent@ucam.edu in temperature and a decrease in precipitation is expected. The available potential future scenarios show higher evapotranspiration, a lower groundwater $(\mathrm{GW})$ recharge and an increase of the sea level. In coastal areas, the problem is exacerbated due to overexploitation, intensifying SWI. Therefore, maintaining acceptable quantity and quality characteristics of GW reserves is important to ensure demand water supply (Sola et al. 2013; Renau-Pruñonosa et al. 2016).

Carlos Llopis-Albert

cllopisa@upvnet.upv.es

1 IGME, Granada, Spain

2 IGME and UCAM, Granada, Spain 
Many investigations have focused on sea-level rise as an important effect of GC on SWI in coastal aquifers (Werner and Simmons 2009; Ferguson and Gleeson 2012; Loáiciga et al. 2012; Benini et al. 2016), but many aquifers are more vulnerable to CC effects on GW recharge and pumping than to sea-level rise (Ferguson and Gleeson 2012; Rasmussen et al. 2013).

An increase in temperature and a decrease in precipitation will force a greater use of available water resources, especially GW. It is due to the recharge decrease and the increase in crop water requirements and, therefore, in the pumping rates. Overexploitation is the main problem in most coastal aquifers, since it produces inland penetration of the saltwater. Therefore, to reduce the impacts of GC on SWI, different adaptation strategies could be applied. They include measures to reduce aquifer demands such as land use and land cover (LULC) changes, modernization and adaptation of irrigation areas and/or economic instruments (Escriba-Bou et al. 2017; Grundmann et al. 2012; Robins et al. 1999). Different measures focused on the offer could be also applied to obtain complementary resources to supply demands, as for example water reuse, desalinations, water transfers and conjunctive use measures (Trinh et al. 2012; McEvoy and Wilder 2012; Pulido-Velazquez et al. 2011).

Many authors have assessed hydrological impacts of CC and/or LULC changes in the SWI phenomenon using sharp interface or density-dependent flow models to simulate hydraulic head and salinity in the aquifer (Pulido-Velazquez et al. 2018; Romanazzi et al. 2015; Klove et al. 2014; Rajan et al. 2006). Potential climate scenarios are defined by simulating future emission scenarios within physically based climatic models [general circulation models (GCMs) and regional climatic models (RCMs)]. Due to the significant bias that usually appears between the historical information and the control simulation of the model, to make this climate information relevant for case study, we need to translate them to the regional local scale by applying some statistical corrections (Collados-Lara et al. 2018). Distributed hydrological models are useful tools to propagate scenarios to assess the impacts on hydrological variables at the specific time and location. Nevertheless, they do not allow drawing direct conclusions about the impacts on SWI (status and vulnerability) at the aquifer scale. For this purpose, an approach such as an index-based method, defined from the output of the model, is a useful tool to analyze this issue. It can also help to summarize SWI problems at the aquifer scale in different periods and identify aquifers in risk of not achieving good chemical status according to the Water Framework Directive (WFD 2000; CHJ 2015).

The vulnerability to contamination in coastal aquifers under future climate scenarios has been previously studied by several authors by employing different vulnerability indices. Li and Merchant (2013) employed a modified
DRASTIC index to model GW vulnerability under future climate and LULC scenarios. Benini et al. (2016) used the GALDIT method to assess vulnerability in the Quinto Basin by employing some CC and LULC change scenarios in a long-term period. They did not use a flow model to simulate salinity and hydraulic head variables. Luoma et al. (2017) assessed the potential impacts of CC on the vulnerability to pollution of an aquifer comparing AVI, SINTACS and GALDIT methods. Although the assessment of vulnerability under future scenarios using an index-based method has been applied by different authors (Huang et al. 2017; Koutroulis et al. 2018), none of them have summarized and analyzed this issue at the aquifer scale.

In Baena-Ruiz et al. (2018), a novel index-based method was proposed to perform an integrated assessment of the global status and vulnerability to SWI in coastal aquifers. The methodology was applied in the Plana de OropesaTorreblanca and Plana de Vinaroz aquifers. It was obtained from hydraulic head and chloride concentration data available in observation wells for the historical period from 1977 to 2015. In that approach, the distributed fields of variables required to define the indices were obtained by applying a simple interpolation method.

This paper intends to achieve a novel objective, to assess the impacts of future GC and CC scenarios on the global status and vulnerability to SWI at the aquifer scale. We propose to perform it by combining a method to summarize SWI at the aquifer scale and the outputs of an integrated method to propagate the impacts of GC scenarios (including adaptation strategies). It intends to contribute to the definition of methods to harmonize the assessment of GC impacts on SWI problems (status and vulnerability) at the aquifer scale. It would not only allow to compare the significance of SWI in different historical and future periods in an aquifer, but also to compare results between different aquifers. The method proposed by Baena-Ruiz et al. (2018) will be adapted to analyze future potential scenarios, since, instead of having a single well-known series (as in the historical period), an infinite number of potential future series are feasible and we analyze some of them. The method will be applied to the Plana de Oropesa-Torreblanca case study, where the impacts of different future GC scenarios are compared. A sensitivity analysis is conducted to assess the influence of $\mathrm{CC}$ on the simulated scenarios.

\section{Methodology}

Figure 1 shows the inputs and the method that we propose to follow to achieve the novel objective. It allows to identify the steps to follow to assess the analyses of impacts of future GC and $\mathrm{CC}$ scenarios at the aquifer scale (considering adaptation strategies to $\mathrm{CC}$ ). 
Fig. 1 Flowchart of the proposed methodology

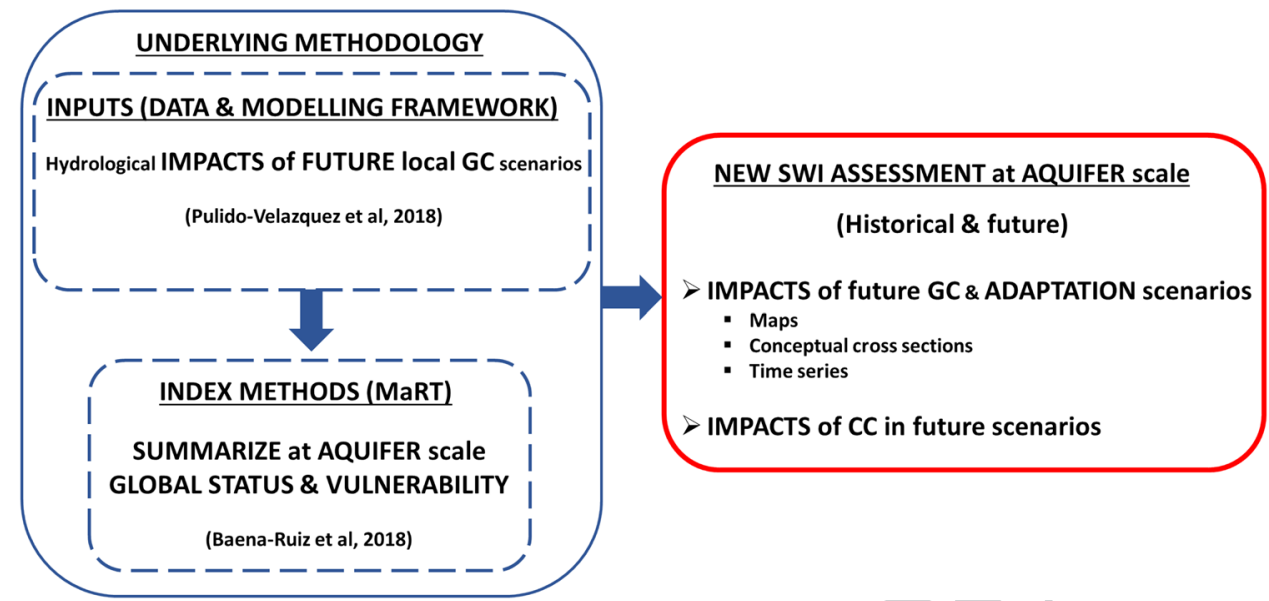

\section{Impacts of future GC scenarios and adaptation scenarios at the aquifer scale}

Baena-Ruiz et al. (2018) proposed a method to summarize the dynamic of the historical status and vulnerability to SWI at the aquifer scale. It was applied to the Plana de Oropesa Torrablanca aquifer, with the required distributed fields (hydraulic head and chloride concentration) obtained by using a simple interpolation method, which was applied to the in situ measurements. These interpolation approaches cannot be employed to assess future scenarios in which we need physical models to propagate the potential future conditions to obtain the cited variable fields. In these cases, the use of a chain of models, which includes a densitydependent flow model, will be required to assess those fields (Pulido-Velazquez et al. 2018).

To summarize the outputs of the models developed in Pulido-Velazquez et al. (2018) in terms of future SWI results (status and vulnerability) at the aquifer scale, we propose to adapt the Baena-Ruiz et al. (2018) method to deal with the particularities of these future potential scenarios. The method will be also employed to analyze future SWI vulnerability, taking into account other intrinsic aquifer parameters (aquifer type and conductivity). To summarize the results, steady pictures (maps of affected area and 2D conceptual cross sections) and lumped indices will be employed. The method will be implemented in a GIS tool that helps to apply it to other case studies.

The maps of chloride concentration are directly obtained from the physical model from Pulido-Velazquez et al. (2018), both for the historical and future periods.

We will also use the definition of affected volume provided by Baena-Ruiz et al. (2018), which is the volume where the chloride concentration level is above the natural background level.

A conceptual cross section, orthogonal to the coastline, will be defined to summarize the SWI status at the aquifer scale. It can be calculated for a specific time and/or for the statistics (eg. mean, minimum, and maximum values) of a period (historical and/or future). It represents the average affected geometry, including the penetration $(P)$ and the affected thickness $\left(\mathrm{Th}_{\mathfrak{a}}\right)$.

$P(m)=\frac{\sum V_{i\left(>V_{\mathrm{r}}\right)}}{T \mathrm{~T}_{\mathrm{a}} \times L_{\mathrm{coast}}}$,

where $V_{i(>V \mathrm{r})}$ is the storage in each cell $\left(\mathrm{m}^{3}\right)$ with a concentration greater than $V \mathrm{r} V_{i\left(>\mathrm{V}_{\mathrm{r}}\right)}\left(\mathrm{m}^{3}\right)=S_{i}\left(\mathrm{~m}^{2}\right) \times b_{i}(\mathrm{~m}) \times \alpha ; V_{\mathrm{r}}$ is the reference threshold (natural background of the aquifer or vulnerability class); $L_{\text {coast }}$ is the length of coastline (m); $S_{i}$ is the surface area of each cell in the model $\left(\mathrm{m}^{2}\right) ; b_{i}$ is the saturated thickness at each instant considered (m); $\alpha$ is the specific yield; $\mathrm{Th}_{\mathrm{a}}$ is the affected thickness $(\mathrm{m})$. It can be calculated as follows:

$\mathrm{Th}_{\mathrm{a}}(\mathrm{m})=\frac{\sum V_{i\left(>V_{\mathrm{r}}\right)}}{\sum S_{i\left(>V_{\mathrm{r}}\right)}}$.

The affected zone has an increment of concentration (IC) above the natural threshold:

$\operatorname{IC}\left(\frac{\mathrm{mg}}{1}\right)=C-V_{\mathrm{r}}$,

where $C$ is the concentration in the affected volume.

$C\left(\frac{\mathrm{mg}}{1}\right)=\frac{\sum\left(C_{i\left(>V_{\mathrm{r}}\right)} \times V_{i\left(>V_{\mathrm{r}}\right)}\right)}{V_{\left(>V_{\mathrm{r}}\right)}}$.

Vulnerability maps were also obtained by applying the GALDIT method (Chachadi and Lobo-Ferreira 2005), which is described in detail in "Appendix". The affected volume is defined as the areas in which the vulnerability is higher than a specific vulnerability class or value (e.g., high vulnerability). A conceptual cross section to 
summarize vulnerability at the aquifer scale could be defined following an analogous reasoning to those applied to assess the status (Baena-Ruiz et al. 2018).

The maps and conceptual cross sections will allow to identify the impacts of future GC scenarios on the aquifer in terms of affected volume by a chloride concentration above the natural background or by a high vulnerability, regarding the historical status. It also allows comparing impacts of different future scenarios on the status and/or vulnerability to SWI.

To assess the dynamic of global status and vulnerability at the aquifer scale, we analyze time series for two lumped indices: "Ma" and "L_GALDIT", respectively. The "Ma" index is defined as "the total additional mass of chloride that causes the concentration in some areas to exceed the natural threshold" (Baena-Ruiz et al. 2018):

$\operatorname{Ma}\left(\frac{\mathrm{kg}}{\mathrm{m}}\right)=P(\mathrm{~m}) \times \operatorname{IC}\left(\frac{\mathrm{mg}}{\mathrm{l}}\right) \times 10^{-3} \times \operatorname{Th}_{\mathrm{a}}(\mathrm{m})$.

In an analogous way, the "L_GALDIT" is defined as the weighted GALDIT index by the aquifer storage:

$\mathrm{L}_{\mathrm{GALDIT}}=\frac{\sum\left(G_{i} \times V_{i}\right)}{V}$,

where $G_{i}$ is the value of GALDIT index in each cell (calculated following the GALDIT method explained in "Appendix"); $V_{i}$ is the storage in each cell; $V$ is the total storage in the aquifer.

In this paper, the dynamic of the lumped indices is analyzed taking into account the particularities of the future scenarios. In a historical assessment, we have a single real climatic series that allows to draw conclusion about the resilience and trend in the aquifer (Baena-Ruiz et al. 2018). But in the assessment of future scenarios, infinite potential future series could be feasible (although we finally considered a limited number of them), and, therefore, the summary of the time series analyses should not be performed in the same way.

In this work, we propose to use a new index, the recovery rate, which can be obtained from the evolution of the global indices Ma and L_GALDIT. It is defined as the mean reduction in the index value in a given period. It may be represented in a box-whisker plot to provide a statistical assessment of the SWI dynamic in future horizons. The recovery rate for Ma index, which represents the mean recovery velocity of the system, is defined as follows:

Recovery rate $=\frac{\mathrm{Ma}_{t}-\mathrm{Ma}_{t-n}}{n}$,

where $\mathrm{Ma}_{t}$ is the global status (Ma index) in a specific date $t$; $\mathrm{Ma}_{t-n}$ is the global status (Ma index) in a specific date $t-n ; n$ is the difference between the date " $t$ " and " $t-n$ " (at monthly scale).

\section{Impacts of CC in future scenarios}

The impacts of CC are analyzed through a sensitivity analysis to quantify the influence of the $\mathrm{CC}$ on the simulated $\mathrm{GC}$ scenarios. We compare the results obtained for the GC scenarios, which include both, future LULC and potential future CC scenarios, and a future LULC scenario defined assuming that there is no $\mathrm{CC}$. The relative differences in the global status (Ma\%) and GW vulnerability (L_GALDIT\%) for those scenarios are obtained with the next expressions:

$\mathrm{Ma} \%=\left(\frac{\mathrm{Ma}(x)-\mathrm{Ma}}{\mathrm{Ma}}\right) \times 100$,

L_GALDIT $\%=\left(\frac{\mathrm{L}_{\text {GALDIT }(x)}-\mathrm{L}_{\text {GALDIT }}}{\mathrm{L}_{\text {GALDIT }}}\right) \times 100$,

where $\mathrm{Ma} \%$ is the variation of the global status (Ma index) due to $\mathrm{CC}$, expressed as a percentage; $\mathrm{Ma}(x)$ is the average global status (Ma index) for each GC scenario; Ma is the average global status index (Ma index) for the LULC scenario; L_GALDIT\% is the variation of the vulnerability (L_GALDIT index) due to CC, expressed as a percentage; L_GALDIT $(x)$ is the average vulnerability (L_GALDIT index) for each GC scenario; L_GALDIT is the average vulnerability index (L_GALDIT) for the LULC scenario.

\section{Description of the study area and available information}

The Plana de Oropesa-Torreblanca is a detrital Mediterranean aquifer, which extends over $75 \mathrm{~km}^{2}$ in the province of Castellon in Spain. It has a length of $21 \mathrm{~km}$ and a width of between 2.5 and $6 \mathrm{~km}$. This Plio-Quaternary aquifer is unconfined and heterogeneous and consists of a silty clay matrix with gravel and sand levels. The aquifer is wedge shaped and it can reach $90 \mathrm{~m}$ thickness near the coast. The transmissivity varies between 300 and $1000 \mathrm{~m}^{2} /$ day (RenauPruñonosa et al. 2016) and the storage coefficient ranges from 2 to $12 \%$. Figure 2 shows the location and hydrogeology of the aquifer.

The wetland Prat de Cabanes is situated in the central zone of the Plana, parallel to the coastline. It extends approximately $9 \mathrm{~km}^{2}$. Its formation is due to the clogging of an old lagoon that is several meters thick. This wetland is separated from the sea by a coastal bar of sorted pebbles.

The aquifer is laterally connected with adjacent aquifers which provide inflows to the system (Giménez and Morell 1997). In addition, the aquifer is fed by infiltration 
Fig. 2 Situation of the study area and hydrogeological sections of precipitation and irrigation returns. Pumped abstraction drains to the Prat de Cabanes wetland and GW discharges to sea compound the outflows to the system (Pulido-Velazquez et al. 2018). Groundwater follows an NW-SE direction under natural conditions (Giménez and Morell 1997; RenauPruñonosa et al. 2016).

\section{Data: hydro-climatic conditions, LULC, and pumping data}

The historical temperature and precipitation data come from the Spain02 project dataset (Herrera et al. 2012, 2016). The monthly average precipitation in the period 1973-2010 varied between 20 and $30 \mathrm{~mm}$ in summer and reached almost $80 \mathrm{~mm}$ in the rainiest month. The monthly average temperature was from 12 to $28{ }^{\circ} \mathrm{C}$ throughout the year.

In the study area, there have been important land use changes from the 1970s. Until 1995 there was a transformation in the crop irrigation, turning it into irrigation lands. From this date to 2010, the main change was an increase of artificial surfaces (mainly residential LULC along the coast) (Feranec et al. 2010) and an improvement in the efficiency of irrigation techniques (CHJ 2015).

Pumping was deduced from historical data. The mean annual pumping in the historical period is $22 \mathrm{hm}^{3} /$ year approximately. The land use changes are reflected in the evolution of total pumping in the Plana de Oropesa-Torreblanca aquifer. First, the transformation into irrigated croplands from 1975 to 1995 produced an increase in pumping from $15 \mathrm{hm}^{3} /$ year to a maximum of $35 \mathrm{hm}^{3} /$ year. It produced a drop in GW level and higher SWI problems. Later, the transformation of irrigation techniques and land uses led to a reduction in pumping to a minimum rate around $13 \mathrm{hm}^{3} /$ year (Pulido-Velazquez et al. 2018).

\section{Future LULC scenarios: implementation} of adaptation measures

The future LULC change scenarios are defined taking into account the urban development planning. It has projected land use changes as mainly the construction of golf courses and the transformation of the land use from agricultural to residential. The main changes in each municipality are the following (Fig. 3).

- In Alcalà de Xivert, there are no expected significant changes.

- The Urban Development Plan for Torreblanca contemplates the land use change from agricultural to residential (70\% of the total area of municipality will be classified as buildable residential or industrial). In the coastal area, north of Prat de Cabanes Natural Park, Doña Blanca Golf Course has been projected.

- In Cabanes and Oropesa municipalities, the integrated development plan Marina d'Or Golf has been approved. It will include three golf courses, private urbanization, hotels and landscapes areas.

To mitigate the impacts of $\mathrm{CC}$ on the GC scenarios, we have also considered the next adaptation measures to increase the complementary resources. These adaptation measures were also requirements included in the urban development plan: the irrigation in the golf courses must be supplied by reclaimed water from residential use and

\begin{tabular}{|l|l|l|l|l|}
\hline Journal : Large 12665 & Article No : 8847 & Pages : 13 & MS Code : 8847 & Dispatch : 17-2-2020 \\
\hline
\end{tabular}




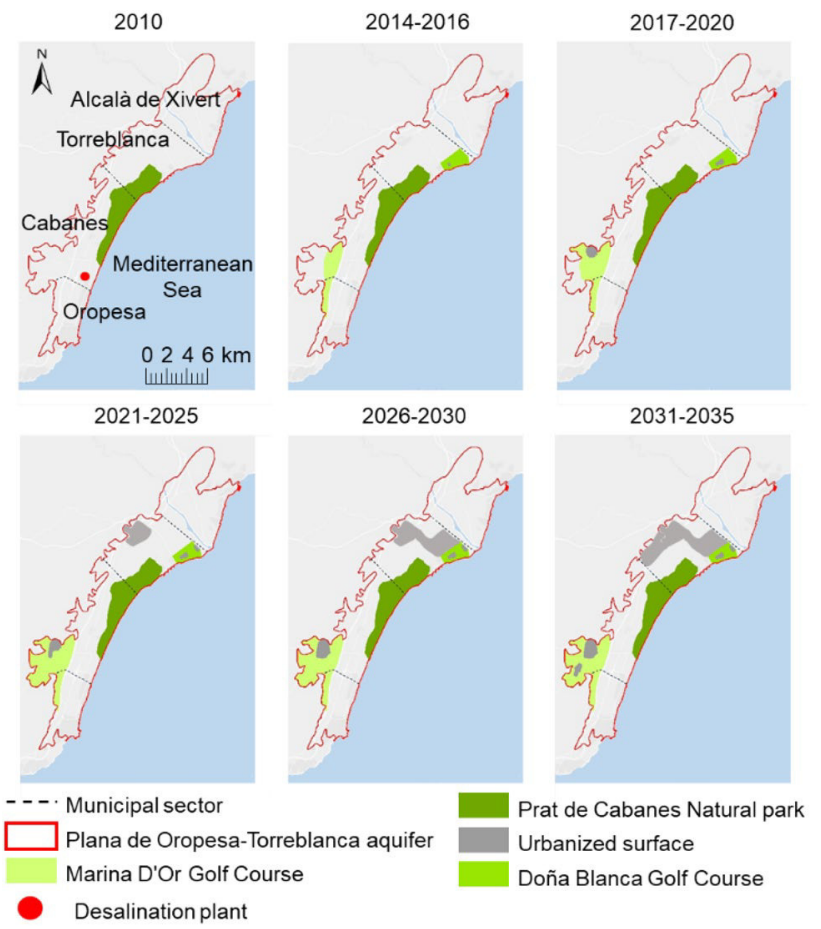

Fig. 3 Expected land use changes in the Plana de Oropesa-Torreblanca aquifer (2010-2035)

water from the desalinization plant will be used for human consumption.

To make the model more realistic, we assume that these land use changes would be executed gradually from 2015 to 2035. Figure 3 shows the evolution of changes in time.

\section{Future GC scenarios and propagation of impacts}

Pulido-Velazquez et al. (2018) generated four potential future climate scenarios (CC scenarios) for Plana de Oropesa-Torreblanca aquifer by employing control and future climatic series data simulated with RCMs in the framework of the CORDEX Project (2013) for the most pessimistic emission scenario RCP8.5. All these climate scenarios showed an increase in mean temperature $\left(\approx 1{ }^{\circ} \mathrm{C}\right.$ on average) with respect to the historical period (1973-2010). The future mean rainfall also showed a decrease (up to $24 \%$ monthly) for every month except September and October, in which a relative increase was predicted (up to $30 \%$ ). These months are the rainiest in the study area and frequent storms occur. The local future scenarios show an increment in these extreme rainfall events (Pulido-Velazquez et al. 2018).

These climate scenarios were combined with a land use change scenario ("Future LULC scenarios. Implementation of adaptation measures"), including some adaptation measures oriented to define more feasible/realistic future scenarios in accordance with the urban development planning, in which complementary resources will be incorporated within the system (water reuse and water from desalination plants for human consumption in the new urban areas).

The next scenarios were finally analyzed.

- Four GC scenarios (GC1, GC2, GC3, GC4) defined by combining four climate scenarios with the future LULC scenario.

- The LULC scenario was defined assuming that there is no CC.

- In the baseline scenario, we assume that the LULC will be maintained as in 2010 and the historical hydro-climatic characteristics will be analogous to those of the period 2006-2010.

A modeling framework was defined with a chain of auxiliary models (rainfall-recharge models, crop irrigation requirements, and irrigation returns models) that provide the inputs to a density-dependent flow model (SEAWAT). It was calibrated from the estimated historical pumping and recharge (deduced from the climate and land use data) ("Data: hydro-climatic conditions, LULC, and pumping data" and "Future LULC scenarios. Implementation of adaptation measures") in the aquifer and the hydraulic head and chloride concentration data available in the observation points during the period 1981-2010. Data from 1973 to 1981 were used to validate it. This model was used to propagate the impacts of the plausible future GC scenarios. It provided a spatio-temporal distribution of the chloride concentration and the hydraulic head evolution for the different GC scenarios. The available volume of resource can be estimated from the hydraulic head and the aquifer geometry. The water budget for each GC scenario was also calculated by using SEAWAT model with the Visual Modflow interface. It allows to understand the system dynamic due to CC and LULC changes.

\section{Results and discussion}

The proposed methodology is applied to Plana de OropesaTorreblanca aquifer to assess the impacts of GC scenarios on SWI at the aquifer scale.

\section{Impacts of future GC scenarios and adaptation scenarios at the aquifer scale}

The six scenarios defined have been simulated by using the SEAWAT model. Field maps of chloride concentration and hydraulic head were previously obtained as output of this model. The area affected by SWI in the aquifer was identified taking into account the natural background in the aquifer, which is $1100 \mathrm{mg} / \mathrm{l}$ of chloride concentration (CHJ 2015; 
Baena-Ruiz et al. 2018). Figure 4 shows the largest affected areas in the historical period and in the future period for different scenarios (future baseline, LULC and GC4). The future baseline and LULC scenarios (defined including the cited adaptation measures) do not show a clear deterioration of the aquifer. The worst hypothetical scenario is the GC4, in which practically the whole aquifer would have a chloride concentration above $1100 \mathrm{mg} / \mathrm{l}$. In GC4 experiments, there was an increment of $10 \%$ in the affected volume compared to the baseline scenario in 2010 (the starting point of the future period in this study). As can be seen in Fig. 4, the aquifer already had a large affected volume in 2010 (more than $80 \%$ ) (Pulido-Velazquez et al. 2018).

The affected areas in terms of high vulnerability are quite similar for the future LULC and baseline scenarios. The GC4 scenario shows a zone of high vulnerability at the north of the aquifer that corresponds with an area with high conductivity.

Due to the applied adaptation strategies, the considered changes in land use (LULC scenario) would not produce a high increase in the maximum values of the affected volume. The reduction of pumping in this LULC scenario would reduce the amplitude of the fluctuations of the affected volumes within the aquifer (Fig. 5a, b). Those non-distributed stresses cause faster fluctuations on the aquifer status. Note that the LULC scenarios are defined assuming that the adaptation measures contemplated within the urban development plan (reduction of pumping due to water reuse and water desalination) will be applied, which would help to reduce the potential impacts of these LULC scenarios on SWI. On the other hand, the waterproofing due to the increase in the residential use contributes to a lower recharge (increasing slightly the mean seawater intrusion volume) in the future and the urbanized area in Torreblanca would continue being supplied with GW.

The GC scenarios (GC1, GC2, GC3, GC4), show an increase in their variability and in the affected volume regarding the baseline scenario, which is obtained from the output of the calibrated SEAWAT model in the historical period and considering the LULC remains as in 2010 and there is no $\mathrm{CC}$ in the future. Taking into account that this increase is not observed in the LULC scenarios, it is mainly due to the impact of CC (Fig. 5a, b). The decrease in pumping in GC scenarios is less significant than the reduction of the inflows in the aquifer (lateral GW inflow + recharge) producing an increase in the affected volume.

All potential future GC scenarios would undergo an increase in the average and maximum affected conceptual
HISTORIC (2010)

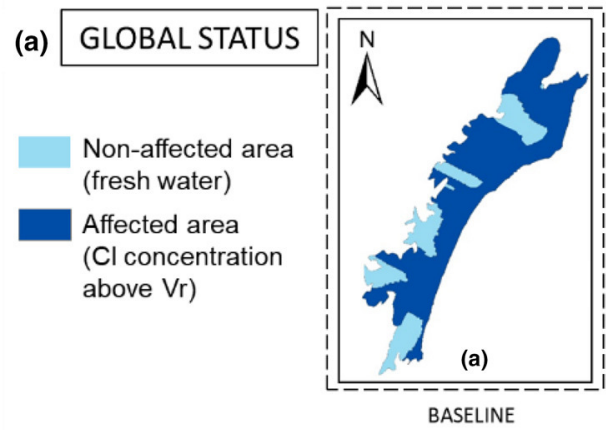

FUTURE

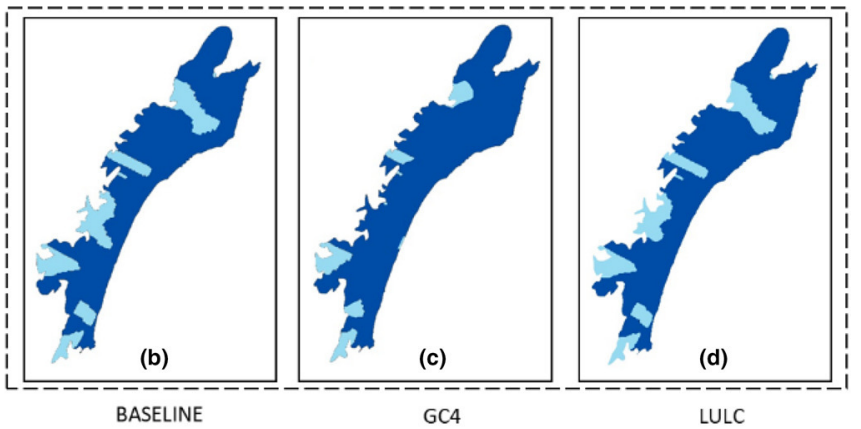

(b)

VULNERABILITY
Non-affected area
(moderate and low
vulnerability)
Affected area
(high vulnerability)

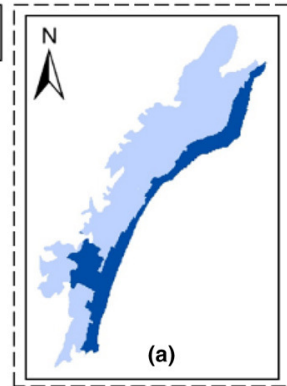

BASELINE

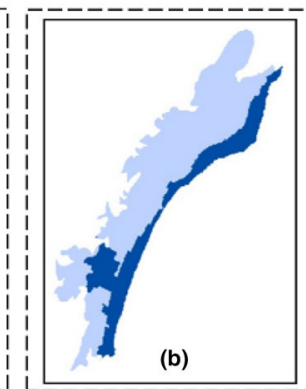

BASELINE

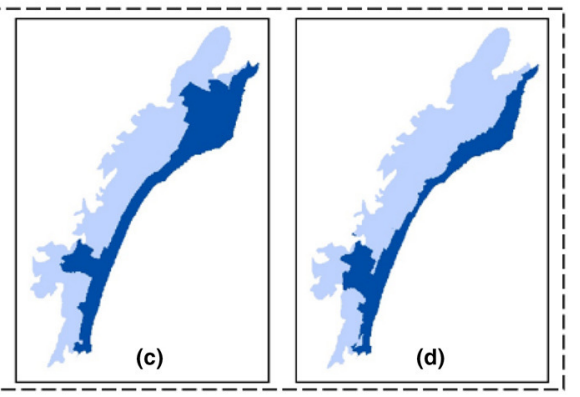

LULC

20 Kilometers

Fig. 4 Maps of affected areas in the years with the largest affected volume: $\mathbf{a}$ chloride concentration and $\mathbf{b}$ vulnerability

\begin{tabular}{|l|l|l|l|l|}
\hline Journal : Large 12665 & Article No : 8847 & Pages : 13 & MS Code : 8847 & Dispatch : 17-2-2020 \\
\hline
\end{tabular}



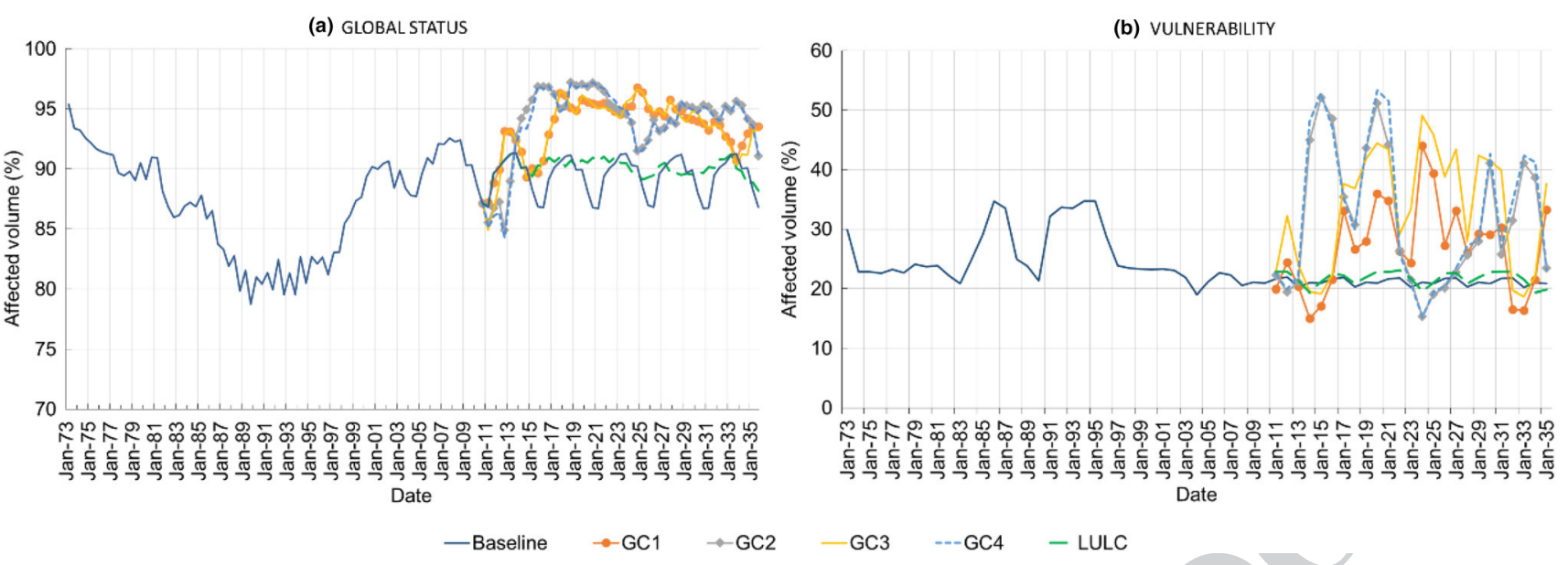

Fig. 5 Evolution of $\mathbf{a}$ affected volume by a chloride concentration above $1100 \mathrm{mg} / \mathrm{l}$ and $\mathbf{b}$ affected volume by high vulnerability

cross section, although the aquifer was largely affected in the historical period (Pulido-Velazquez et al. 2018). The LULC scenario (including adaptation measures) does not show substantial changes in the affected areas with respect to the baseline scenario, while GC3 and GC4 scenarios involve the largest affected area in the aquifer (Fig. 6). The expected future climatic conditions would have a negative impact on the salinization of the aquifer resources and its vulnerability to SWI.

The global indices (Ma and L_GALDIT) calculated for the baseline, LULC and the GC scenarios (Fig. 7) show that LULC changes would not produce a clear deterioration of the global status and vulnerability of the aquifer. The continuous growing trend (in the LULC and GC scenarios) in the Ma index observed from 2025 (Fig. 7b) is related to the impacts of the planned urbanization of a large area in Torreblanca, which produces an increase of chloride concentrations. GC scenarios forecast a large affected mass in the future, which is mainly due to the potential climatic conditions. The maximum values of the lumped indices ( $\mathrm{Ma}$ and L_GALDIT) during the GC scenarios are induced by periods with high temperature and low precipitation.

The LULC scenario does not produce significant changes in the vulnerability. The vulnerability is more sensitive to
Fig. 6 Average historical and maximum future affected cross sections (linear dimensions in kilometers. Vertical exaggeration scale: 500)

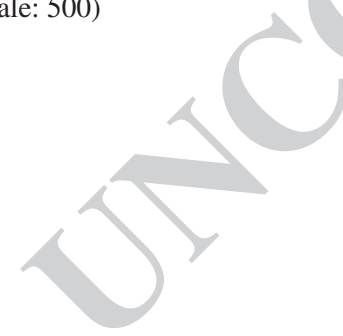

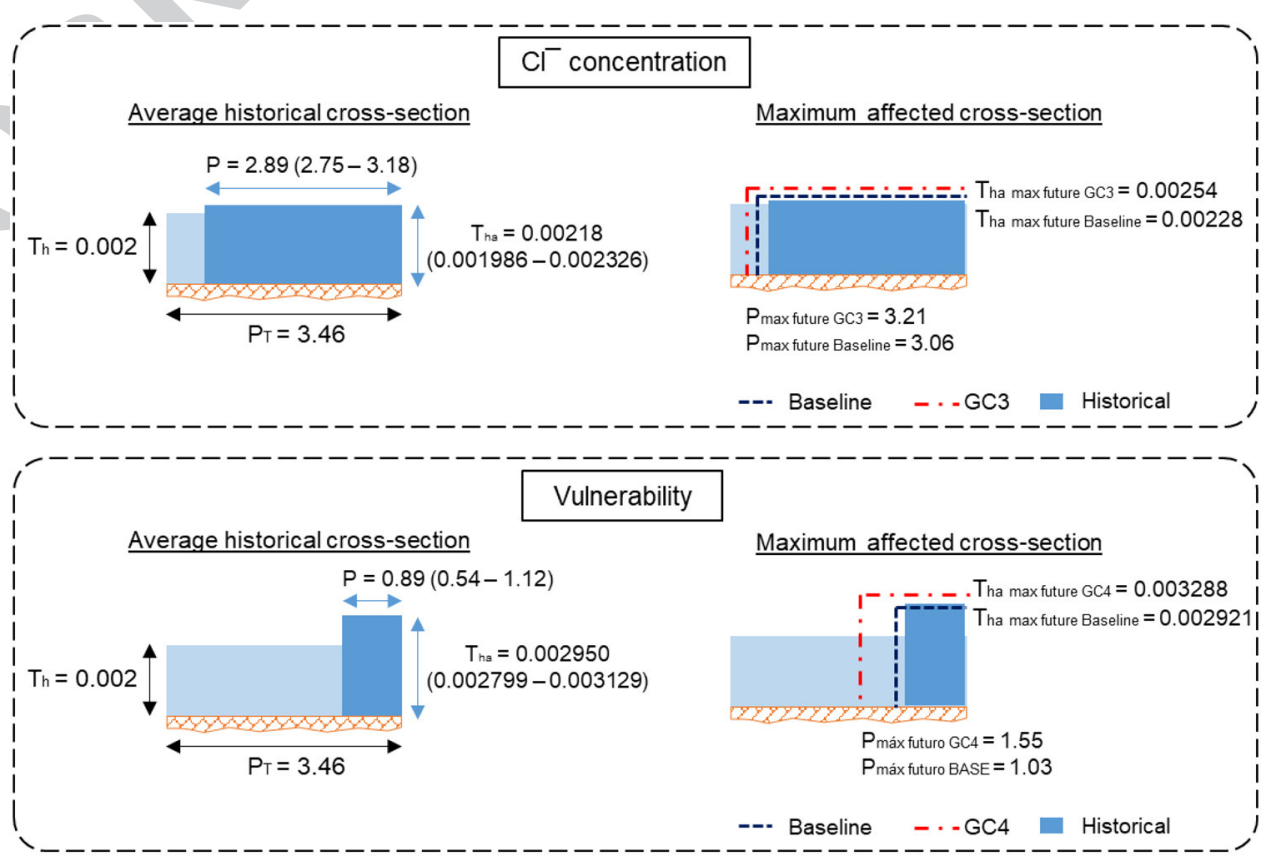

Non-affected area

\begin{tabular}{|l|l|l|l|l|}
\hline Journal : Large 12665 & Article No : 8847 & Pages : 13 & MS Code : 8847 & Dispatch : 17-2-2020 \\
\hline
\end{tabular}




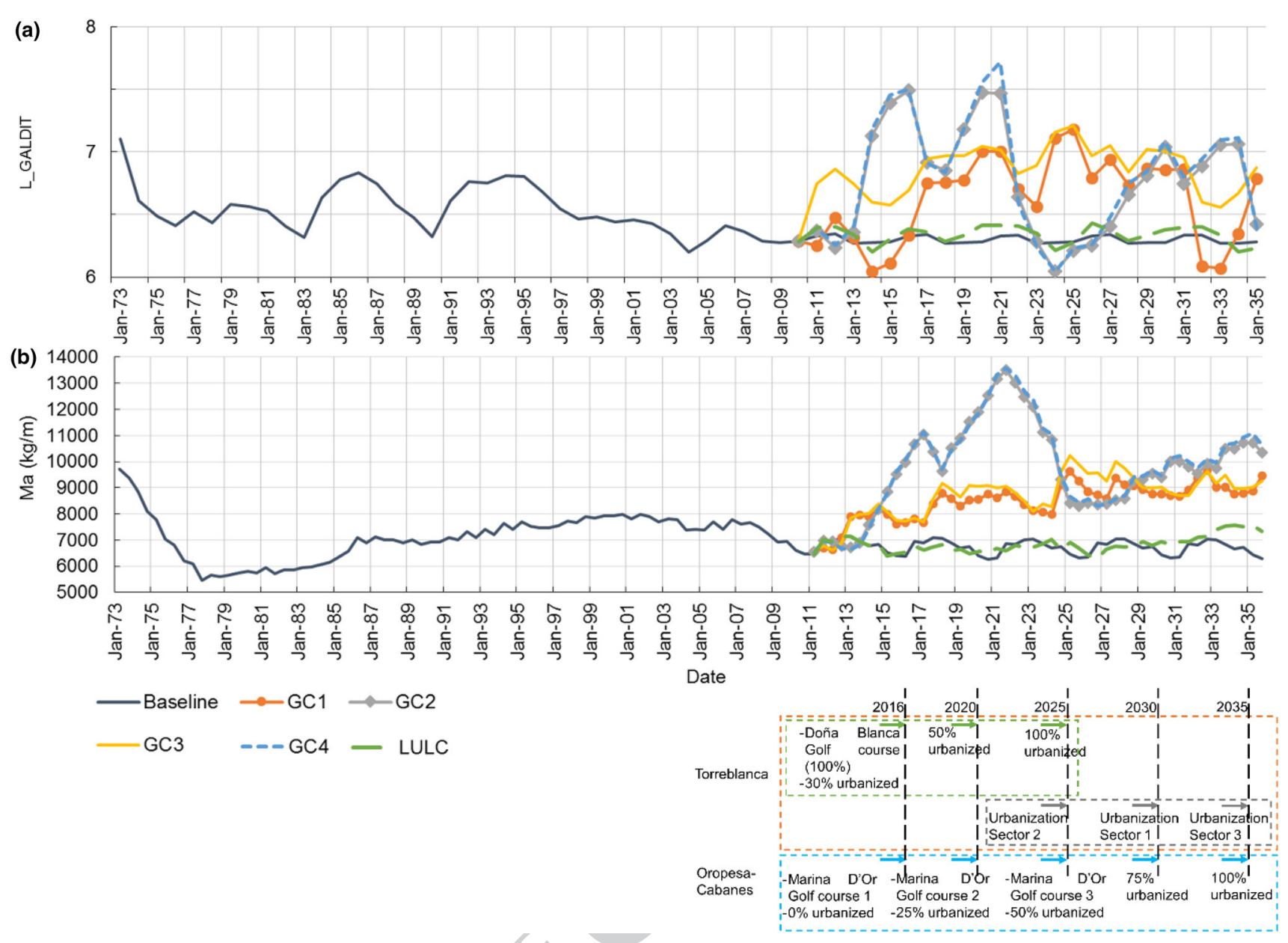

Fig. 7 Lumped indices for vulnerability and global status: a L_GALDIT index; b Ma index

the GC scenarios. All of them show a significant increase in its variability and a mean increase in the vulnerability, but there are some periods in which the vulnerability even decreases (Fig. 7a).

The resilience and trend of the lumped indices were analyzed for the historical period in Baena-Ruiz et al. (2018). In $\mathrm{CC}$ studies, we cannot analyze the trend of the indices due to the uncertainty of the chronological sequence. Instead, the recovery rate is assessed as described in the methodology. Figure 8 shows that the aquifer is able to respond to the severe climatic conditions estimated in GC scenarios. Based on the calibrated model, GC2 and GC4 scenarios present more extreme values, but also show higher recovery rates.

\section{Impacts of CC in future scenarios}

A sensitivity analysis was carried out to evaluate the impact of CC on the global status and vulnerability to SWI at the aquifer scale. The LULC (without CC) scenario provides us information about the sensitivity of the results to CC.

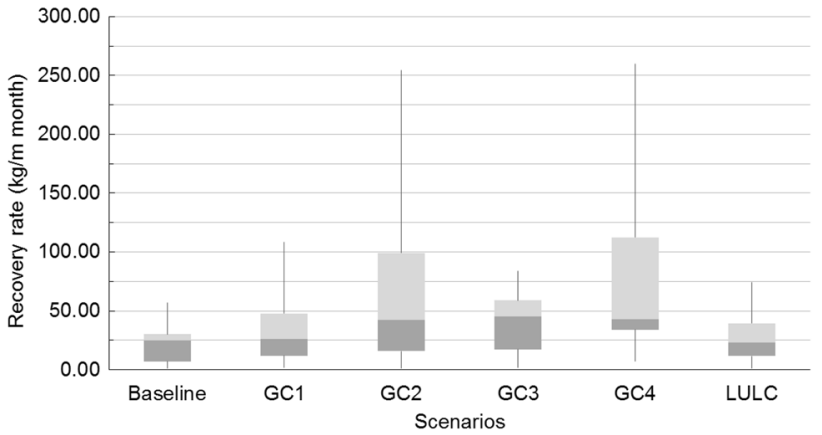

Fig. 8 Statistics of recovery rate for baseline, LULC and GC scenarios

Figure 9 represents the increase (\%) in $\mathrm{Ma}$ and $\mathrm{L}_{-} \quad 515$ GALDIT due to the CC. It shows that CC would have a 516 significant impact on Ma index (related to global status of 517 the aquifer). Vulnerability is less sensitive to CC due to other 518 factors that are used in the index (conductivity and distance $\quad 519$

\begin{tabular}{|l|l|l|l|l|}
\hline Journal : Large 12665 & Article No : 8847 & Pages : 13 & MS Code : 8847 & Dispatch : 17-2-2020 \\
\hline
\end{tabular}




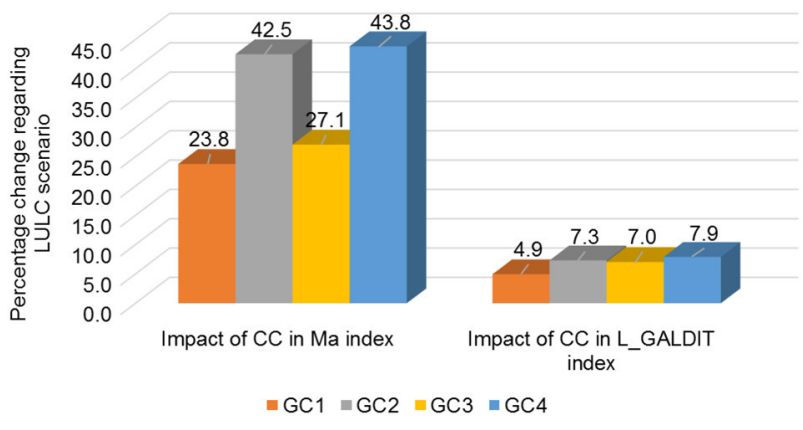

Fig. 9 Sensitivity analysis of CC in lumped indices

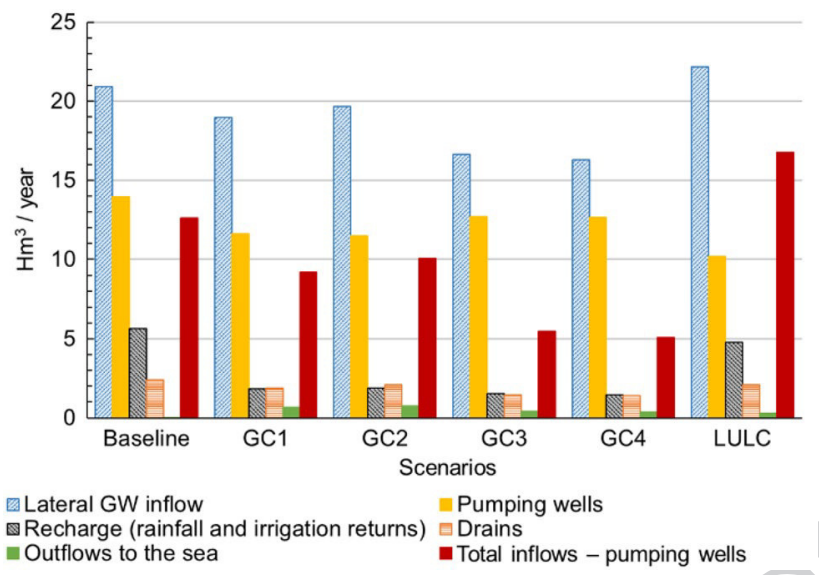

Fig. 10 Mean annual values of the budget four GC, LULC and baseline scenarios

from the coast), which have greater weight and are invariant in time.

Taking into account these results, $\mathrm{CC}$ would produce significant impacts on the global status of the aquifer.

The mean annual values of the budget for the six scenarios was calculated by running the density-dependent flow model in Visual Modflow (Pulido-Velazquez et al. 2018). Figure 10 shows the mean annual values of the affected components of the budget for the six scenarios. It also includes the deficit in the resource produced in the system due to both GC and/or exploitation in this aquifer. Red bars in Fig. 10 show the difference between total inflows and pumping.

In the future LULC scenario and the four GC scenarios, the pumping is reduced due to changes in land use and the proposed adaptation measures (water reuse for irrigation and water from desalinization plant for human consumption in the new urban areas) defined in accordance with the urban development plan, but also the recharge (direct and lateral) decreases due largely to $\mathrm{CC}$ and waterproofing of the land in the Torreblanca area and urbanization.

Figure 10 also shows that the GC scenarios (especially GC4) experience a larger reduction in the total budget than the LULC scenario. Therefore, the impact of CC is greater than that of the improvement caused by LULC. This result is consistent with Fig. 4, where GC4 was the largest affected area. It is due to GC4 scenario experiments a small decrease in pumping due to LULC changes and adaptation measures, but the inflows (lateral and recharge) decrease still further $\mathbf{Q 0 5}_{7}$ (Fig. 10).

Therefore, in summary, we have obtained results to analyze the potential future impact of GC and LULC scenarios on SWI in a coastal aquifer. They show a significant increase in the magnitude and variability of the affected volume for the GC scenarios compared to the baseline scenario. PulidoVelazquez et al (2018) also highlighted the higher variability observed for these GC scenarios when they analyzed the flow budget.

The potential future scenarios would produce a negative impact on the salinization of the aquifer resources and in its vulnerability to SWI, which is in agreement with results observed in previous studies in the Mediterranean area (Mabrouk et al. 2018). The decrease in recharge will exacerbate SWI problems (Liu et al. 2008; Petty 2011), producing a great effect in the affected mass of the aquifer, whose distribution and magnitude will depend on the scenarios (Van Pham and Lee 2015).

The sensitivity analysis performed to assess the impacts of $\mathrm{CC}$ shows that it has a higher influence on aquifer status than on its vulnerability. This is because GALDIT does not consider explicitly the recharge variable, although it controls aquifer salinization. These conclusions are in agreement with those of a previous study (Benini et al. 2016).

Finally, the comparison between LULC and baseline scenarios reveals that pumping is a key factor in the SWI problem in coastal areas. This conclusion has been supported by other authors (Van Pham and Lee 2015).

\section{Hypothesis and limitations}

In this section, we summarize the hypothesis assumed in this analysis. They have been classified into two categories. Inputs for the method

- Historical climatic data are taken from Spain02 dataset. They are considered to properly fit the historical period (1973-2010).

- LULC is supposed to be executed gradually from 2015 to 2035 .

- CC scenarios data for the period (2011-2035) were taken considering the most pessimistic emission scenario published by the IPCC in the AR5 report (RPC8.5) and many assumptions were from Pulido-Velazquez et al. (2018).

- The generation of local CC scenarios and the propagation of its impacts were assessed through a chain of auxiliary models and a SEAWAT model whose reliability 
depends on assumptions and data considered in calibration (Pulido-Velazquez et al. 2018). We consider as inputs of the proposed method the local CC scenarios and their impacts obtained by propagating the modeling framework (Pulido-Velazquez et al. 2018).

\section{Method}

- The natural background or reference level to identify SWI was taken from CHJ (2015). The results are sensitive to the adopted value (Baena-Ruiz et al. 2018).

- This general method provides lumped results and information about local potential impacts that may be lost in the aggregation process.

\section{Conclusions}

In this paper, an integrated methodology is applied to assess the hydrological impacts of GC scenarios on the global status and vulnerability to SWI at the aquifer scale.

The novelty of this paper consists in the harmonization of the impacts of GC scenarios in the global status and vulnerability to SWI at the aquifer scale including some management strategies. It allows to compare the significance of the SWI problems in different historical and future periods for an aquifer and between different aquifers. The effect of CC in the GC scenarios is also analyzed. The method has been implemented in a GIS tool that helps to apply it to any case study.

Results show that GC scenarios would imply a greater deterioration in the aquifer than LULC scenario. The adaptation strategies will produce a reduction of pumping in some areas of the aquifer, which would reduce the impacts of the potential future LULC and GC scenarios. The lumped indices reveal that GC would involve more variability in SWI problems (global status and vulnerability) and CC would increase the degradation of the aquifer. On average, it is expected that a greater area affected by intrusion and extreme climatic conditions might produce an increase in the vulnerability of the aquifer. GC would produce a greater impact on SWI global status than in the aquifer's vulnerability. Nevertheless, the resilience capacity of the aquifer would allow recovering from the impacts of the extreme climatic conditions.

The main contribution of this paper is the analysis of impacts of future GC scenarios in the SWI problem at the aquifer scale. It allows to obtain general conclusions about the global status and vulnerability and to assess the effects of CC and adaptation strategies. Due to the sensitivity of the method to the natural background, a proper assessment of it is important to achieve realistic results. This method also helps to understand the effect of adaptation measures to cope with the growing water requirements. It reveals that complementary adaptation strategies are needed to cope with CC.

Acknowledgements This work has been partially supported by the GeoE.171.008-TACTIC project from GeoERA organization funded by European Union's Horizon 2020 research and innovation program and the Plan de Garantía Juvenil from MINECO (Ministerio de Economía y Competitividad), co-financing by BEI (Banco Europeo de Inversiones) and FSE (Fondo Social Europeo). The authors also thank AEMET and UC for the data provided for this work (Spain02 dataset, https://www. meteo.unican.es/datasets/spain02).

\section{Appendix}

\section{Galdit method}

GALDIT was proposed by Chachadi and Lobo-Ferreira (2005) to assess the vulnerability to SWI.

This method considers that there are six parameters/ variables influencing the vulnerability to SWI: aquifer type, hydraulic conductivity, height of GW level above sea level, distance from the shore, impact of existing status of SWI and thickness of aquifer.

A rate of importance is assigned to the parameters according to the value or characteristics of each parameter.

The values of the parameters are weighted by a factor to obtain the GALDIT index:

GALDIT index $=\frac{\sum_{i=1}^{6}\left(W_{i} \times R_{i}\right)}{\sum_{i=1}^{6} W_{i}}$,

where $W_{i}$ is the weight of the $i$ th indicator and $R_{i}$ is the importance rating of the $i$ th indicator.

The GALDIT index is classified into three vulnerability levels:

- GALDIT $\geq 7.5 \rightarrow$ high vulnerability.

- $7.5>$ GALDIT $\geq 5 \rightarrow$ moderate vulnerability.

- GALDIT $<5 \rightarrow$ low vulnerability.

\section{References}

Baena-Ruiz L, Pulido-Velazquez D, Collados-Lara AJ, Renau-Pruñonosa A, Morell I (2018) Global assessment of seawater intrusion problems (status and vulnerability). Water Resour Manage 32:2681-2700. https://doi.org/10.1007/s11269-018-1952-2

Benini L, Antonellini M, Laghi L (2016) Assessment of water resources availability and groundwater salinization in future climate and land use change scenarios: a case study from a coastal drainage basin in Italy. Water Resour Manage 30:731-745. https ://doi.org/10.1007/s11269-015-1187-4

Chachadi AG, Lobo-Ferreira JP (2005) Assessing aquifer vulnerability to sea-water intrusion using GALDIT method: part 2-GALDIT indicator descriptions. IAHS and LNEC. In: Proceedings of the
669

670 
4th The Fourth Inter Celtic Colloquium on Hydrology and Management of Water Resources, held at Universidade do Minho, Guimarães, Portugal, July 11-13, 2005

CHJ (Júcar Water Agency) (2015) Júcar River Basin Plan. Confederación Hidrográfica del Júcar https://www.chj.es/es-es/medioambie nte/planificacionhidrologica/Paginas/PHC-2015-2021-Plan-Hidro logico-cuenca.aspx. Accessed 21 Oct 2019

Collados-Lara A-J, Pulido-Velazquez D, Pardo-Igúzquiza E (2018) An integrated statistical method to generate potential future climate scenarios to analyse droughts. Water 10:1224-1248. https://doi. org/10.3390/w10091224

CORDEX PROJECT (2013) The Coordinated Regional Climate Downscaling Experiment CORDEX. Program sponsored by 20 World Climate Research Program (WCRP). https://wcrp-cordex.ipsl.jussi eu.fr/. Accessed 21 Oct 2019

Escriva-Bou A, Pulido-Velazquez M, Pulido-Velazquez D (2017) Economic value of climate change adaptation strategies for water management in Spain's Jucar basin. J Water Res Plan Manag 143(5):04017005. https://doi.org/10.1061/(ASCE)WR.19435452.0000735

Feranec J, Jaffrain G, Soukup T, Hazeu G (2010) Determining changes and flows in European landscapes 1990-2000 using CORINE land cover data. Appl Geogr 30(1):19-35. https://doi.org/10.1016/j. apgeog.2009.07.003

Ferguson G, Gleeson T (2012) Vulnerability of coastal aquifers to groundwater use and climate change. Nat Clim Change 2(5):342-345

Giménez E, Morell I (1997) Hydrogeochemical analysis of salinization processes in the coastal aquifer of Oropesa (Castellón, Spain). Environ Geol 29(1-2):118-131. https://doi.org/10.1007/s0025 40050110

Grundmann J, Schütze N, Schmitz GH, Al-Shaqsi S (2012) Towards an integrated arid zone water management using simulation-based optimisation. Environ Earth Sci 65(5):1381-1394

Herrera S, Gutiérrez JM, Ancell R, Pons MR, Frías MD, Fernández J (2012) Development and analysis of a 50 year high-resolution daily gridded precipitation dataset over Spain (Spain02). Int J Climatol 32:74-85. https://doi.org/10.1002/joc.2256

Herrera S, Fernández J, Gutiérrez JM (2016) Update of the Spain02 gridded observational dataset for euro-CORDEX evaluation: assessing the effect of the interpolation methodology. Int J Climatol 36:900-908. https://doi.org/10.1002/joc.4391

Huang L, Zeng G, Liang J, Hua S, Yuan Y, Li X, Liu J (2017) Combined impacts of land use and climate change in the modeling of future groundwater vulnerability. J Hydrol Eng 22(7):05017007. https://doi.org/10.1061/(ASCE)HE.1943-5584.0001493

Kløve B, Ala-Aho P, Bertrand G, Gurdak JJ, Kupfersberger H, Kværner J, Uvo CB (2014) Climate change impacts on groundwater and dependent ecosystems. J Hydrol 518:250-266. https://doi. org/10.1016/j.jhydrol.2013.06.037

Koutroulis AG, Papadimitriou LV, Grillakis MG, Tsanis IK, Wyser K, Betts RA (2018) Freshwater vulnerability under high end climate change. A pan-European assessment. Sci Total Environ 613:271286. https://doi.org/10.1016/j.scitotenv.2017.09.074

Li R, Merchant JW (2013) Modeling vulnerability of groundwater to pollution under future scenarios of climate change and biofuelsrelated land use change: a case study in North Dakota, USA. Sci Total Environ 447:32-45. https://doi.org/10.1016/j.scito tenv.2013.01.011

Liu J, Rich K, Zheng C (2008) Sustainability analysis of groundwater resources in a coastal aquifer. Alabama Environ Geol 54(1):4352. https://doi.org/10.1007/s00254-007-0791-x

Loáiciga HA, Pingel TJ, Garcia ES (2012) Sea water intrusion by sealevel rise: scenarios for the 21st century. Groundwater 50(1):3747. https://doi.org/10.1111/j.1745-6584.2011.00800.x
Luoma S, Okkonen J, Korkka-Niemi K (2017) Comparison of the AVI, modified SINTACS and GALDIT vulnerability methods under future climate-change scenarios for a shallow low-lying coastal aquifer in southern Finland. Hydrogeol J 25(1):203-222. https:// doi.org/10.1007/s10040-016-1471-2

Mabrouk M, Jonoski A, Oude HP, Essink G, Uhlenbrook S (2018) Impacts of sea level rise and groundwater extraction scenarios on fresh groundwater resources in the Nile Delta Governorates. Egypt. Water 10(11):1690. https://doi.org/10.3390/w10111690

McEvoy J, Wilder M (2012) Discourse and desalination: potential impacts of proposed climate change adaptation interventions in the Arizona-Sonora border region. Glob Environ Change 22(2012):353-363. https://doi.org/10.1016/j.gloen vcha.2011.11.001

Petty K (2011) The effects of land cover, climate, and urbanization on groundwater resources in Dauphin Island. Dissertation, Auburn University, Alabama

Pulido-Velazquez D, Garrote L, Andreu J, Martin-Carrasco FJ, Iglesias A (2011) A methodology to diagnose the effect of climate change and to identify adaptive strategies to reduce its impacts in conjunctive-use systems at basin scale. J Hydrol 405:110-122. https://doi.org/10.1016/j.jhydrol.2011.05.014

Pulido-Velazquez D, Renau-Pruñonosa A, Llopis-Albert C, Morell I, Collados-Lara AJ, Senent-Aparicio J, Baena-Ruiz L (2018) Integrated assessment of future potential global change scenarios and their hydrological impacts in coastal aquifers-a new tool to analyse management alternatives in the Plana Oropesa-Torreblanca aquifer. Hydrol Earth Syst Sci 22(5):3053. https://doi.org/10.5194/ hess-22-3053-2018

Ranjan SP, Kazama S, Sawamoto M (2006) Effects of climate and land use changes on groundwater resources in coastal aquifers. J Environ Manage 80(1):25-35. https://doi.org/10.1016/j.jenvm an.2005.08.008

Rasmussen P, Sonnenborg TO, Goncear G, Hinsby K (2013) Assessing impacts of climate change, SLR, and drainage canals on saltwater intrusion to coastal aquifer. Hydrol Earth Syst Sci 17:421-443. https://doi.org/10.5194/hess-17-421-2013

Renau-Pruñonosa A, Morell I, Pulido-Velazquez D (2016) A methodology to analyse and assess pumping management strategies in coastal aquifers to avoid degradation due to seawater intrusion problems. Water Resour Manage 30(13):4823-4837. https://doi. org/10.1007/s11269-016-1455-y

Robins NS, Jones HK, Ellis J (1999) An aquifer management case study - the chalk of the English South Downs. Water Resour Manage 13(3):205-218. https://doi.org/10.1023/A:1008101727356

Romanazzi A, Gentile F, Polemio M (2015) Modelling and management of a Mediterranean karstic coastal aquifer under the effects of seawater intrusion and climate change. Environ Earth Sci 74(1):115-128. https://doi.org/10.1007/s12665-015-4423-6

Sola F, Vallejos A, Moreno L, López-Geta JA, Pulido-Bosch A (2013) Identification of hydrogeochemical process linked to marine intrusion induced by pumping of a semi-confined Mediterranean coastal aquifer. Int J Environ Sci Technol 10(1):63-76. https://doi. org/10.1007/s 13762-012-0087-x

Trinh LT, Nguyen G, Vu H, Van Der Steen P, Lens RNL (2012) Climate change adaptation indicators to assess wastewater management and reuse options in the Mekong Delta. Vietnam Water Resour Manag 27(5):1175-1191. https://doi.org/10.1007/s1126 9-012-0227-6

Van Pham H, Lee SI (2015) Assessment of seawater intrusion potential from sea-level rise and groundwater extraction in a coastal aquifer. Desalination Water Treat 53(9):2324-2338. https://doi. org/10.1080/19443994.2014.971617

Water Framework Directive (WFD) (2000) Directiva 2000/60/CE del Parlamento Europeo y del Consejo de 23 de Octubre de 2000. 
Diario Oficial de las Comunidades Europeas de 22/12/2000. L 327/1-327/32

Werner AD, Simmons CT (2009) Impact of sea-level rise on sea water intrusion in coastal aquifers. Groundwater 47(2):197-204. https ://doi.org/10.1111/j.1745-6584.2008.00535.x
Publisher's Note Springer Nature remains neutral with regard to jurisdictional claims in published maps and institutional affiliations.
820 821

822 
Article: $\quad \mathbf{8 8 4 7}$

\section{Author Query Form}

\section{Please ensure you fill out your response to the queries raised below and return this form along with your corrections}

Dear Author

During the process of typesetting your article, the following queries have arisen. Please check your typeset proof carefully against the queries listed below and mark the necessary changes either directly on the proof/online grid or in the 'Author's response' area provided below

\begin{tabular}{|l|l|l|}
\hline Query & Details Required & Author's Response \\
\hline AQ1 & $\begin{array}{l}\text { Author: We have deleted duplicate affiliations }[1,3] \text { and }[4,5], \text { kindly check and } \\
\text { confirm. }\end{array}$ & \\
\hline AQ2 & Author: Please check the edit to the article title. & \\
\hline AQ3 & $\begin{array}{l}\text { Author: Please check the clarity of the sentence 'Until 1995 there was a transformation } \\
\text { in the crop... }\end{array}$ & \\
\hline AQ4 & $\begin{array}{l}\text { Author: Please check the edit to the sentence 'In GC4 experiments, there was an } \\
\text { increment of 10\% in the... }\end{array}$ & \\
\hline AQ5 & $\begin{array}{l}\text { Author: Please check the clarity of the sentence 'It is due to GC4 scenario experiments } \\
\text { a small decrease...' }\end{array}$ \\
\hline AQ6 & $\begin{array}{l}\text { Author: Please check the edit to the sentence 'On average, it is expected that a greater } \\
\text { area affected by intrusion...' }\end{array}$ & \\
\hline
\end{tabular}

